\title{
Management Accounting and Control System
}

\author{
Rewan Kumar Dahal \\ Lecturer, Nepal Commerce Campus
}

\begin{abstract}
A larger entity of the cost management system which assists executives in fulfilling organizational objectives is known as management accounting and control system (MACS). It is used for planning, monitoring and control of different organizational activities, to optimize the use of resources, to support the process of decision making and to the performance evaluation process. The scope of the MACS can be divided into two broad groups: technical considerations and behavioral considerations. Technical considerations fall into two categories: (i) the relevance of information generated and (ii) the scope of the system like the value chain, total life cycle costing, target costing, kaizen costing, benchmarking, balanced scorecard etc. whereas the behavioral consideration involves individuals and their behavior within organizations.
\end{abstract}

Key words - Management accounting control system (MACS), value chain, total life cycle costing, target costing, kaizen costing, benchmarking, balanced scorecard and behavioral consideration.

\section{Introduction}

Accounting systems may not only be used to enable economically sensible decisions, it may also serve as 'rationalization' devices for decisions already made. A cost management system is one of the central performance measurement systems. A larger entity of the cost management system is known as management accounting and control system (Atkinson et al., 2014). It is defined as the process of identification, measurement, accumulation, analysis, preparation, interpretation and communication of financial and non-financial information that assists executives in fulfilling organizational objectives. In the other words, it is a formal mechanism of gathering and communicating data for the ends of aiding and coordinating collective decisions in the light of the overall goals or objectives of an organization. Therefore, management accounting and control system (MACS) is used for planning, monitoring and control of different organizational activities, to optimize the use of resources, to support the process of decision making and to the performance evaluation process. 
The tools and techniques of management accounting and control systems have to be understood not only in terms of their technical functioning, but also with respect to their relationship to the organizational context in which they are embedded. Therefore, the scope of the MACS can be divided into two broad groups: technical considerations and behavioral considerations as presented at figure 1 .

\begin{tabular}{|c|c|c|}
\hline \multicolumn{3}{|c|}{ Figure 1 Scope of MACS } \\
\hline & \multicolumn{2}{|c|}{ Management Accounting and Control System } \\
\hline & & $\nabla$ \\
\hline \multicolumn{2}{|c|}{ Technical Considerations } & Behavioral Considerations \\
\hline \multicolumn{2}{|c|}{ - The relevance of the information generated: } & - Embedding the organization's ethical \\
\hline - & Accurate & code of conduct into MACS design \\
\hline - & Timely & \\
\hline - & Consistent & - Using a mix of short and long-term \\
\hline - & Flexible & qualitative and quantitative \\
\hline & & performance measures (i.e. Balance \\
\hline \multicolumn{2}{|c|}{ - The scope of system: } & scorecard approach) \\
\hline - & The Value chain & \\
\hline- & Total life cycle costing & - Empowering employees to be \\
\hline - & Target costing & involved in decision making and \\
\hline - & Kaizen costing & MACS design \\
\hline - & Benchmarking & \\
\hline- & Balanced scorecard & $\begin{array}{l}\text { - Developing an appropriate incentive } \\
\text { system to reward performance }\end{array}$ \\
\hline
\end{tabular}

\section{Technical Considerations in MACS}

Technical considerations fall into two categories: (i) the relevance of information generated and (ii) the scope of the system.

(i) The relevance of information generated

The relevance of information is measured by four characteristics:

- Accurate: Management accounting provides accurate information to users. Inaccurate information is not relevant or useful for decision making because it is misleading. Designers have to develop a system that leads to the most accurate information possible, subject to a cost-benefit trade-off.

- Timely: Information has an objective. There are usually periods within which these objectives operate. Good information neither is produced too frequently nor is compiled after it is need most. Accurate information that is late is also of little use for decision making. The MACS must be designed so that the results of performance measurement are feedback to the appropriate units in the most expedient way possible.

- Consistent: Designers must structure the MACS to provide a consistent framework that can be applied globally across the units or divisions of 
an entity. Consistency means that the language used and the technical methods of producing management accounting information do not conflict within various parts of an organization.

- Flexible: MACS designers must allow users to use the system's available information in a flexible manner so that they can customize its application for local decisions. If flexibility is not possible, a user's (an employee's) motivation to make the best decision may be lessened for the decision at hand, especially if different units engage in different types of activities.

\section{(ii) The scope of the system}

The scope of the MACS must be comprehensive and include all activities across the entire value chain of the organization. For example, historically, many MACS measure and assess performance in only one part of the value chain - the actual production or throughput process. The performance of suppliers, the design activities, and the postproduction activities associated with products and services are ignored. Without a comprehensive set of information, managers can make only limited decisions. Therefore, MACS includes the following:

\section{The Value Chain}

The concept of value chain analysis was developed by Michael Porter in 1985. The value chain describes the full range of activities that firms and workers do to bring a product from its conception to its end use and beyond. This includes activities such as design, production, marketing, distribution and support to the final consumer. The activities that comprise a value chain can be contained within a single firm or divided among different firms. Value chain activities can produce goods or services, and can be contained within a single geographical location or spread over wider areas. This concept evaluates the value that is added by each and every activity in the organization. A sequence of activities that should contribute more to the ultimate value of the product than to its cost as shown figure 2:

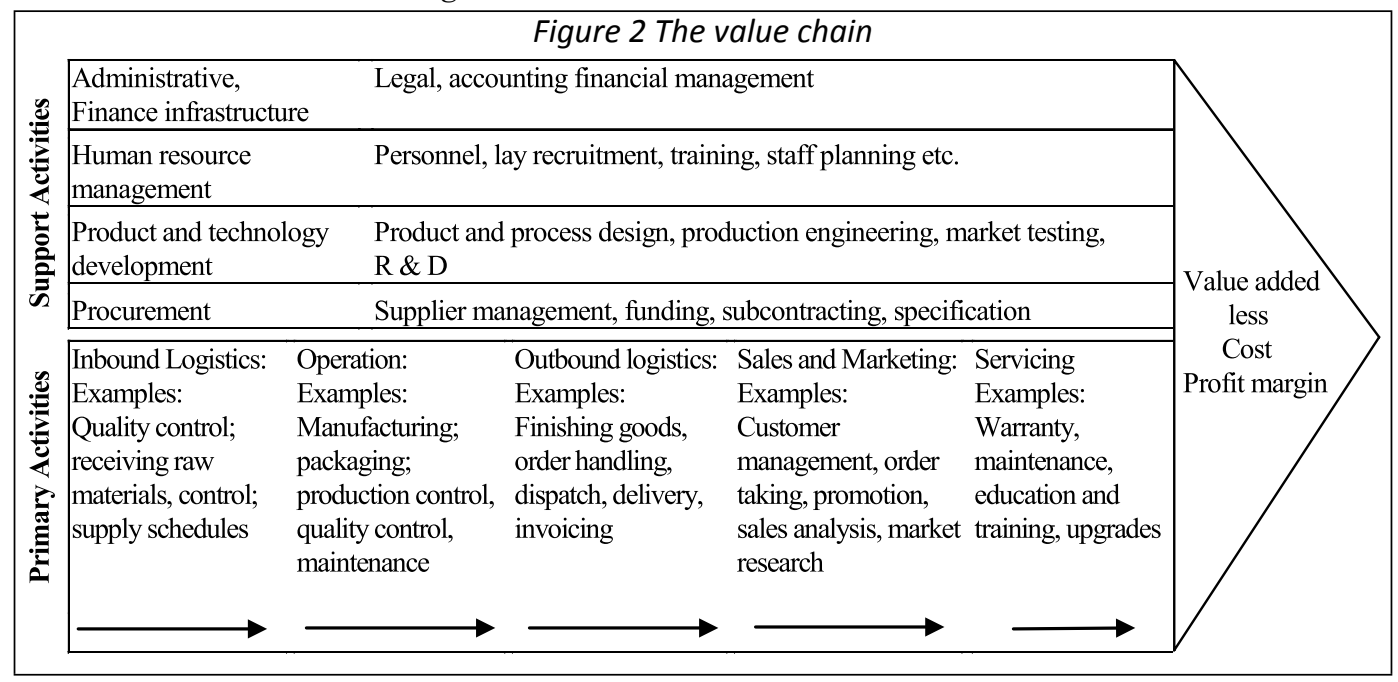




\section{Total Life Cycle Costing}

In the changing business environment, companies are seeking new ways of providing additional value to customers and gain a competitive edge over their competitors. The total-life-cycle costing (TLCC) approach is a comprehensive way for managers to understand and manage costs through a product's design, development, manufacturing, marketing, distribution, maintenance, service, and disposal stages as presented figure 3 (Atkinson et al., 2014). It refers to the process of managing all costs along the value chain. Numerous life-cycle costs concepts, such as research development and engineering and post-sales service and disposal, have emerged in various functional areas of business. Although each concept is useful within its respective area, a TLCC perspective integrates the concepts so that they can be understood in their entirety. From the manufacturer's perspective, total-life-cycle product costing integrates functional life-cycle concepts into following three stages.

$\underbrace{\begin{array}{c}\text { Figure 3 Total life-cycle costing } \\ \text { Manufacturing Cycle }\end{array}}_{\begin{array}{c}\text { Target Costing \& } \\ \text { Value Engineering } \\ \begin{array}{c}\text { Engineering Cycle } \\ \text { Total Life Cycle Costing }\end{array}\end{array}} \underbrace{\begin{array}{c}\text { Post-sale Service } \\ \text { and Disposal Cycle }\end{array}}_{\begin{array}{c}\text { Activity-Based Costing } \\ \text { Kaizen Costing }\end{array}}$

TLCC is the name of the process of managing all costs along the value chain. TLCC is also known as managing costs 'from the cradle to the grave'. The fundamentals of TLCC is to identify and quantify the various cost elements in purchasing and using a particular product or service including annualized cost that would be incurred through its life. Traditionally, businesses looked at just the purchasing costs of an assets while making decisions. However, the cost to a company does not stop there, after the asset has been purchased, there are operational costs, maintenance costs, upgrade costs, depreciation costs, and finally the residual cost or the disposal cost. TLCC takes into account all these attributes while assigning the cost to an assets. Therefore, it enables businesses to compare assets before making a purchase decision.

\section{Target Costing}

Target costing is a technique which developed, in the early 1970s in Japanese manufacturing industry, as consumer demand for more diversified and customized products. Sakurai (1989) defines target costing as a 'cost management tool for reducing the overall cost of a product over its entire life cycle with the help of the production, engineering, R\&D, marketing, and accounting departments'. Similarly, according to the CIMA Official Terminology a target cost is 'a product cost estimate derived by subtracting a desired profit margin from a competitive market price.' Implementing target costing within the organization requires lot of efforts and discipline and all the 
supply chain partners must find ways to reduce costs as they design, manufacture and distribute the components. Target costing helps engineers design new products that meet customers' expectations and that can be manufactured at a desired cost. It is an important management accounting method for cost reduction during the design stage of a product's life cycle and one that can explicitly help to manage total-life-cycle costs. Its goal is to design costs out of products in the RD\&E stage of a product's total life cycle rather than the more costly way of trying to reduce them during the manufacturing stage. Figure 4 shows that how does the target costing work?

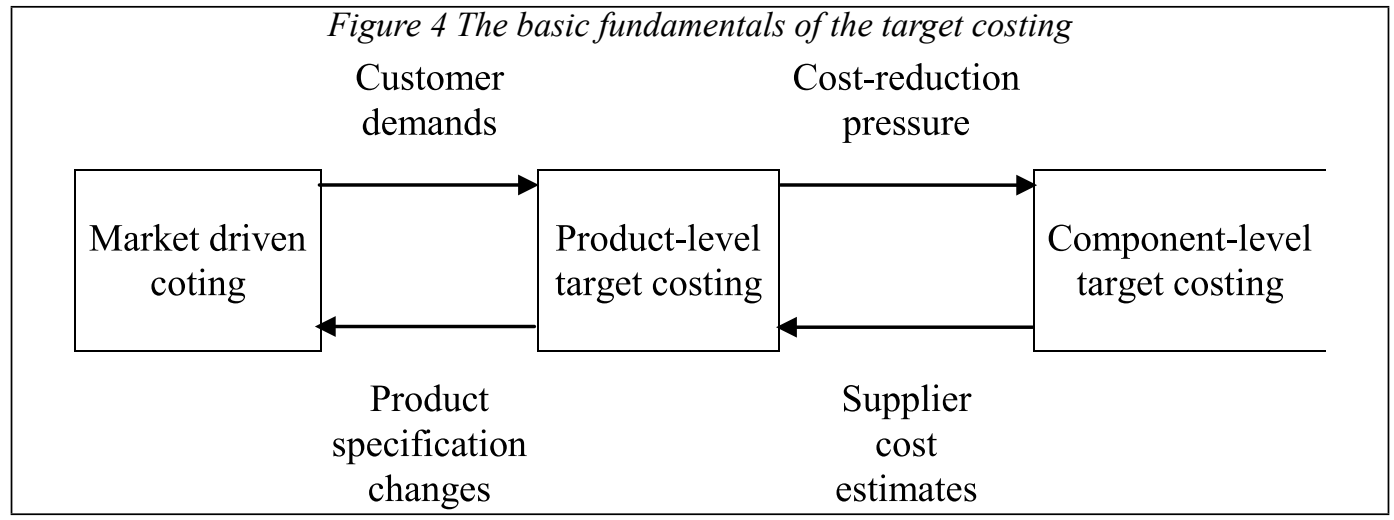

This is a customer-driven technique that requires in-depth market research to assess the need and perceived value of the product by the customer. The costing system establishes profit margin based on expected return on investment of the organization and then expressed as a percentage on the selling price, which is deducted to the term target profit to determine target cost. The target cost is then compare with the estimated cost and establishes cost reduction targets for each components using value engineering and value analysis.

\section{Kaizen Costing}

The term kaizen is originated by the Japanese companies for continuous improvement. The Japanese word kaizen is a composition of the words kai and zen where kai, means "change" and zen, means "good or better" and can be translated as improvement as depicted in figure 5. The popular meaning of kaizen is continual incremental improvement in all aspects of a company especially gradual, orderly, continual improvement or change for better. The kaizen concept involves everyone in an organization working together to make incremental improvements without large capital investment. Imai (1986) defined kaizen as continuing improvement in personal life, home life, social life, work life and when it is applied to the workplace then kaizen means continuing improvement involving everyone from top managers to workers. In business culture and management process the term kaizen refers for continual and gradual improvement. The kaizen approach is not only about doing things better, but getting specific outcomes. 


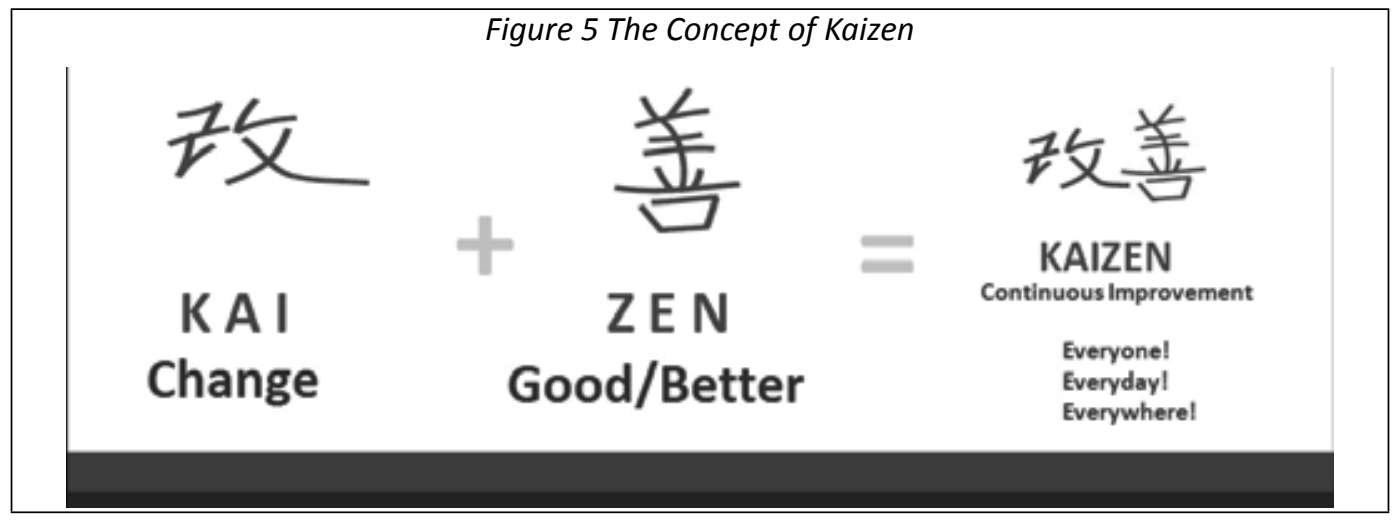

Kaizen costing is a system that provides relevant data to cost management systems. It focuses on reducing costs during the manufacturing stage of the total life cycle of a product. Its goal is to ensure that a product meets or exceeds customer requirements for quality, functionality, and prices in order to compete effectively. For example, if a manufacturing firm is able to reduce the actual production costs than the prior year cost, it is assumed that there is an application of Kaizen costing. If the cost of disruptions to production are greater than the savings, then it will not be applied. Figure 6 shows the general process of kaizen implementation.

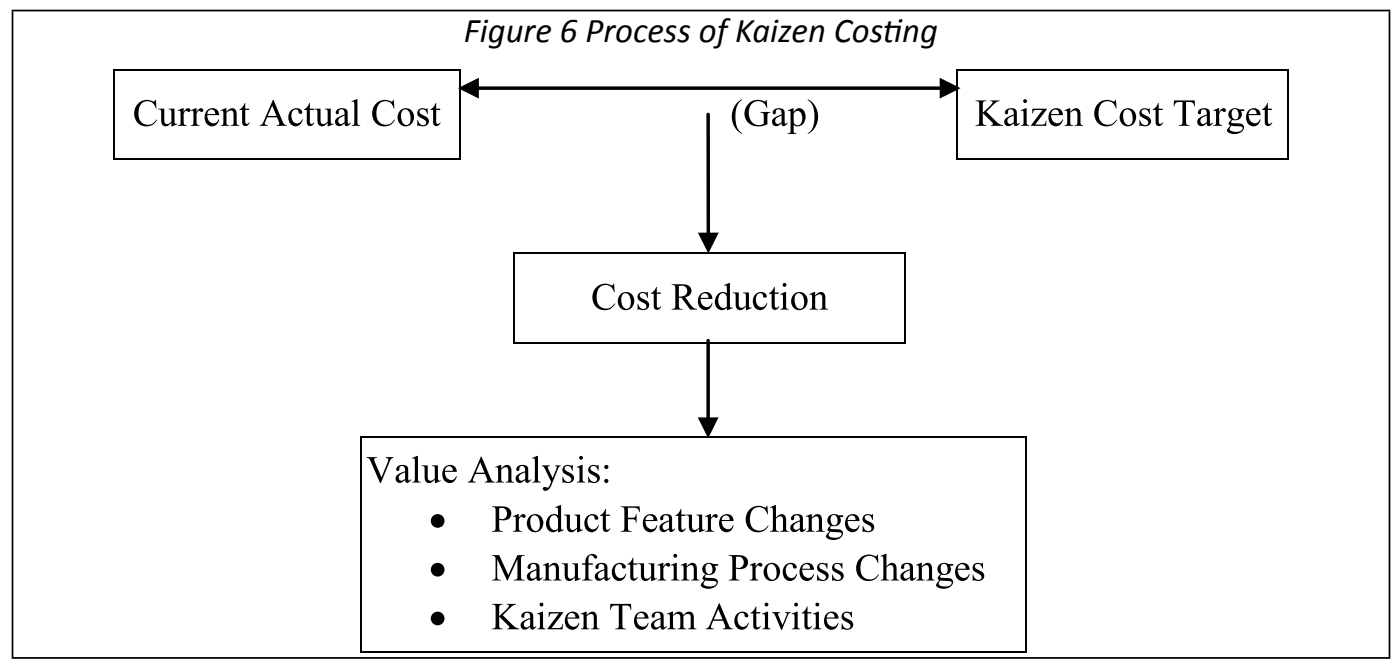

\section{Benchmarking}

Benchmarking is the process of improving performance by continuously identifying, understanding, and adapting outstanding practices and processes found inside and outside an organization (company, public organization, university, college, etc.). It was pioneered by Xerox Corporation in the 1979s, as part of their response to international competition in the photocopier market, and originated from reverse engineering of competitors' products. Its scope was then enlarged to include business 
services and processes.

Benchmarking of business processes is usually done with top performing companies in other industry sectors. This is feasible because many business processes are essentially the same from sector to sector. Benchmarking focuses on the improvement of any given business process by exploiting 'best practices' rather than merely measuring the best performance. Best practices are the cause of best performance. Companies studying best practices have the greatest opportunity for gaining a strategic, operational, and financial advantage. The systematic discipline of benchmarking is focused on identifying, studying, analyzing, and adapting best practices and implementing the results. To get the most value from the benchmarking process consistently, senior management may discover the need for a significant culture change. That change, however, unleashes benchmarking's full potential to generate large paybacks and strategic advantage.

Benchmarking is classified on the basis of the type of partner selected for the benchmarking. The partnership team (or, organization/groups/system/process) may be from the same company or from different organization. Based on the approaches, benchmarking is classified into four groups as presented in figure 7 .

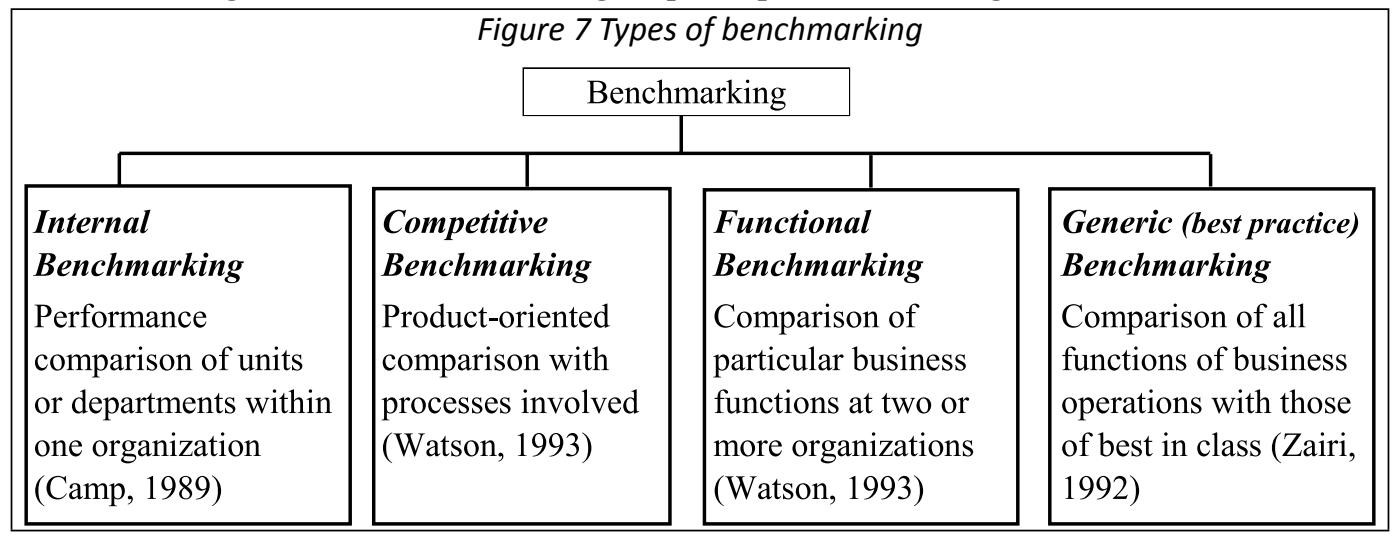

The benchmarking process involves comparing one's firm performance on a set of measurable parameters of strategic importance against that of firms' known to have achieved best performance on those indicators. It identifies the gap (performance gap) between an organization's performance and the desired performance (best-practice performance) on a specific measure, such as on-time delivery, number of defectives, or employee satisfaction and take actions to meet or exceed the benchmark. Development of benchmarks is an iterative and ongoing process that is likely to involve sharing information with other organizations working with them towards an agreeable metrology.

\section{Balanced scorecard}

Performance measurement system is considered information system that is used to evaluate both individual and organizational performance. In the business world, organizational performance matters most. Historically, literature concerning 
performance measurement can be divided into two phases (Ghalayini, Noble \& Crowe, 1997). The first phase started in the 1880s and ended in the 1980s. This phase emphasized financial measures of performance such as profit, return on investment and return on assets. The second phase began in the early 1980s and started to consider non-financial measures too.

Various performance measurement frameworks have been developed since 1980s with integrating both financial and non-financial measures. One of the mostly preferred framework is balanced scorecard. This framework proposed that the company should use a balanced set of performance measures incorporating financial and nonfinancial perspectives as depicted in figure 8 and has been adopted by different types of organizations. The framework considers nonfinancial measures are leading indicators, they predict future financial performance rather than simply report what has already happened whereas financial measures are lagging indicators and they report the results of past decision and confirm long-term trends.

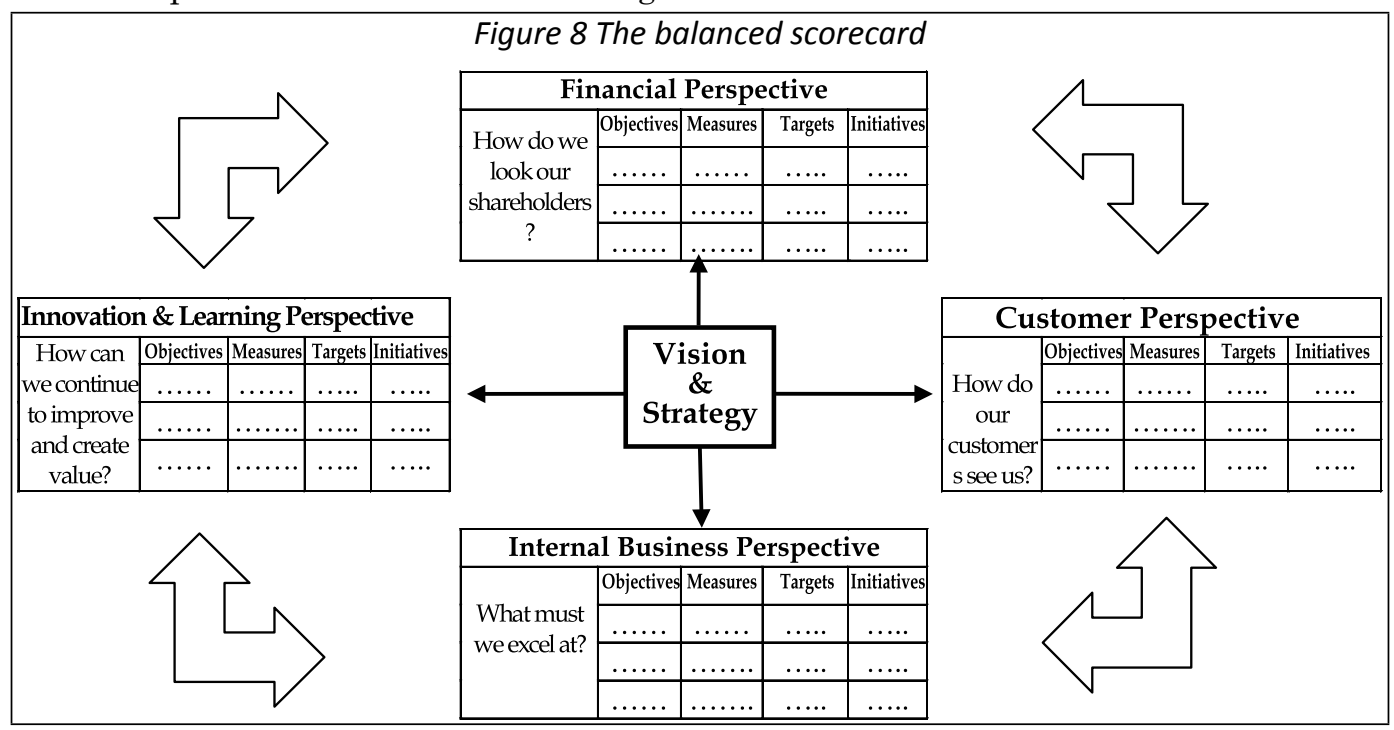

The balanced scorecard is a management system that enables organizations to clarify their vision and strategy and translate them into action through:

$\rightarrow$ Objectives - what the strategy is to achieve in that perspective;

$\rightarrow \quad$ Measures - how progress for that particular objective will be measured;

$\rightarrow \quad$ Targets - refer to the target value that the organization seeks to obtain for each measure;

$\rightarrow \quad$ Initiatives - what will be done to facilitate the reaching of the target?

The balanced scorecard provides feedback of both the internal business processes and external outcomes, which allows for continuous improvement of strategic performance and results. Therefore, it is considered as nerve system of an enterprise. The term 'scorecard' signifies quantified performance measures and 'balanced' signifies the system is balanced between (i) short-term and long-term objectives; (ii) financial 
and non-financial measures; (iii) lagging and leading indicators; and (iv) internal and external performance perspectives. It provides a system for measuring and managing all aspects of an organization's performance at the following four perspectives:

Financial perspectives: The financial perspective considers of maximizing shareholders wealth as the ultimate goal of a company. The financial measures convey the economic consequences for the actions already taken by the organization, and focus on the profitability related measures on which the shareholders verify the profitability of their investment.

Customer perspectives: The customer perspective describes how a company intends to attract, retain, and deepen relationships with targeted customers by differentiating itself from competitors.

Internal business perspectives: The internal business process perspective identifies the critical operation management, customer management, innovation, and regulatory and social processes in which the organization must excel to achieve its customers, revenue growth, and profitability objectives.

Innovation and learning perspectives: Innovation and growth perspective of the balanced scorecard is related to the employees of the organization, and measures the extent to which the organization exerts efforts to provide its employees with opportunities to grow and learn in their domain. It identifies the objectives for the people, information technology, and organizational alignment that will drive improvement in the various process objectives.

\section{Behavioral Considerations in MACS}

Management control system involves individuals and their behavior within organizations. Controls seek to influence individual behavior in order to achieve organizational objectives. Control aims at producing goal congruent behavior. To illustration the concept of goal congruent, we can divide an organization into two groups, management and subordinates. The respective goal of these two groups and the resultant attainment of the goals of the organization to which they belong are illustrated in figure 9 . 


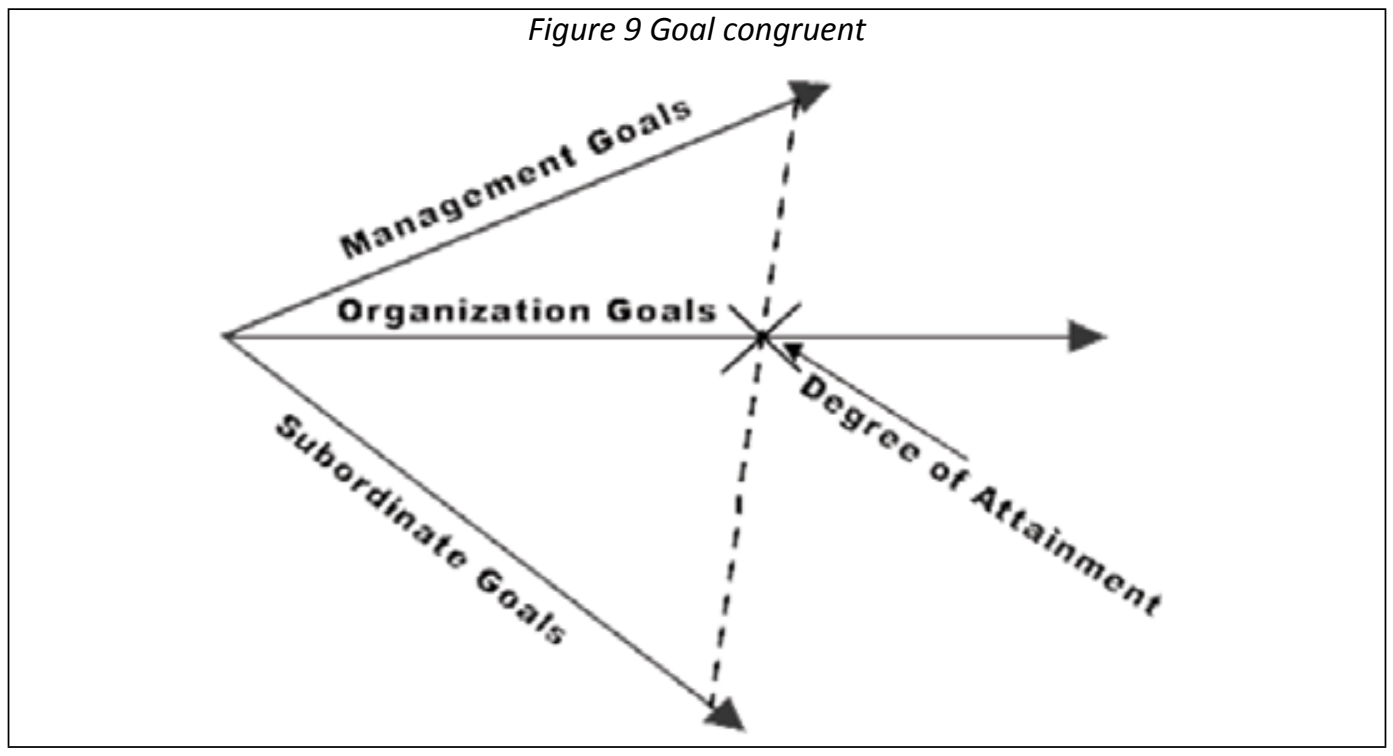

Management control ensures that individual and organizational behavior effectively contribute towards the attainment of the organizational goals. Human interests and motivation can vary significantly, a major role for control systems is to motivate behavior congruent with the desires of the organization. Four major behavioral characteristics should be considered when designing a management accounting control system (Atkinson et al., 2014):

- $\quad$ Embedding the organization's ethical code of conduct into MACS design;

- Using a mix of short and long-term qualitative and quantitative performance measures;

- Empowering employees to be involved in decision making and MACS design and

- Developing an appropriate incentive system to reward performance

\section{Embedding the organization's ethical code of conduct into MACS design}

A boundary system is a set of standards relating to acceptable behavior in an organization. MACS should incorporate the principles of an organization's code of ethical conduct. MACS that incorporates ethical principles can provide decision makers with guidance as they face ethical dilemmas. Managers often play a significant role in MACS design. Their behavior and decision making are guided by the organization's code of conduct and the ethical standards under which they abide. Managers try to establish systems that they do not have to personally monitor on a regular basis. These are called diagnostic control systems. These are feedback systems that monitor organizational outcomes and correct any deviations form predetermined performance standards. Interactive systems need the manager to have a dialogue among all organizational participants about the data received. Both these systems has two common methods: task control and result control. For the first one - it is the 
process of finding ways to control the human behavior so that the job is completed in the prescribed manner. Task control can be divided into two categories - preventative control and monitoring. Results control: the performance of the employee against stated objectives. For results control to be effective the organization must have clearly defined objectives, communicated them to the appropriate organization member and designed performance measures consistent with the objectives.

\section{Using a mix of short and long-term qualitative and quantitative performance measures (i.e. balanced scorecard approach)}

When an organization choose performance measures without careful consideration, non-goal-congruent behavior can occur. For example, when a supplier is measured whether he/she delivers on time, the supplier may deliver on time but quality may be sacrificed. When employees are so focused on performance it can lead to dysfunction behavior- he/she can manipulate or falsifying performance measures. When employees attempt to manipulate performance through job related acts, this is known as gaming performance indicator. The ways in which organizations measure performance send signals to all employees and stakeholders about what the organization considers as its priorities. Using multiple measures of performance (i.e. financial and non-financial measures) helps employees focus on several dimensions of their jobs rather than just keying in on one dimension. The measurement system conveys what the organization values, how the individual contributes to what the organization values, and what the employee should do to earn personal rewards and satisfaction. Therefore, if the performance measurement system does not measure some facet of performance, the system not only provides no direct motivation to the employee, who receives no personal benefit in pursuing unmeasured performance goals, but also implies to the employee that the particular facet of performance is irrelevant.

\section{Empowering employees to be involved in decision making and MACS design}

Empowering employees in MACS design requires two essential elements: (i) allowing employees to participate in decision making, and (ii) ensuring that employees understand the information they are using and generating.

Participation in decision making: The employees are the biggest asset of an organization, by letting them participate in the decision making process has two benefits - better morale and greater job satisfaction - this leads to higher productivity and employees feel that they have ownership and control over they do at work.

Education to understand the information used and generated: It is not only managers that need to understand the information generated and used but also the employees, decisions are only as good as the information they are based upon. A continuous education on changing MACS needs to be in place. 


\section{Developing an appropriate incentive system to reward performance}

The final behavioral consideration in MACS design is to consider the most appropriate reward systems to further motivate employees. Organizations use both financial and non-financial reward system to motivate employees, they include: intrinsic rewards and extrinsic rewards as presented in figure 10.

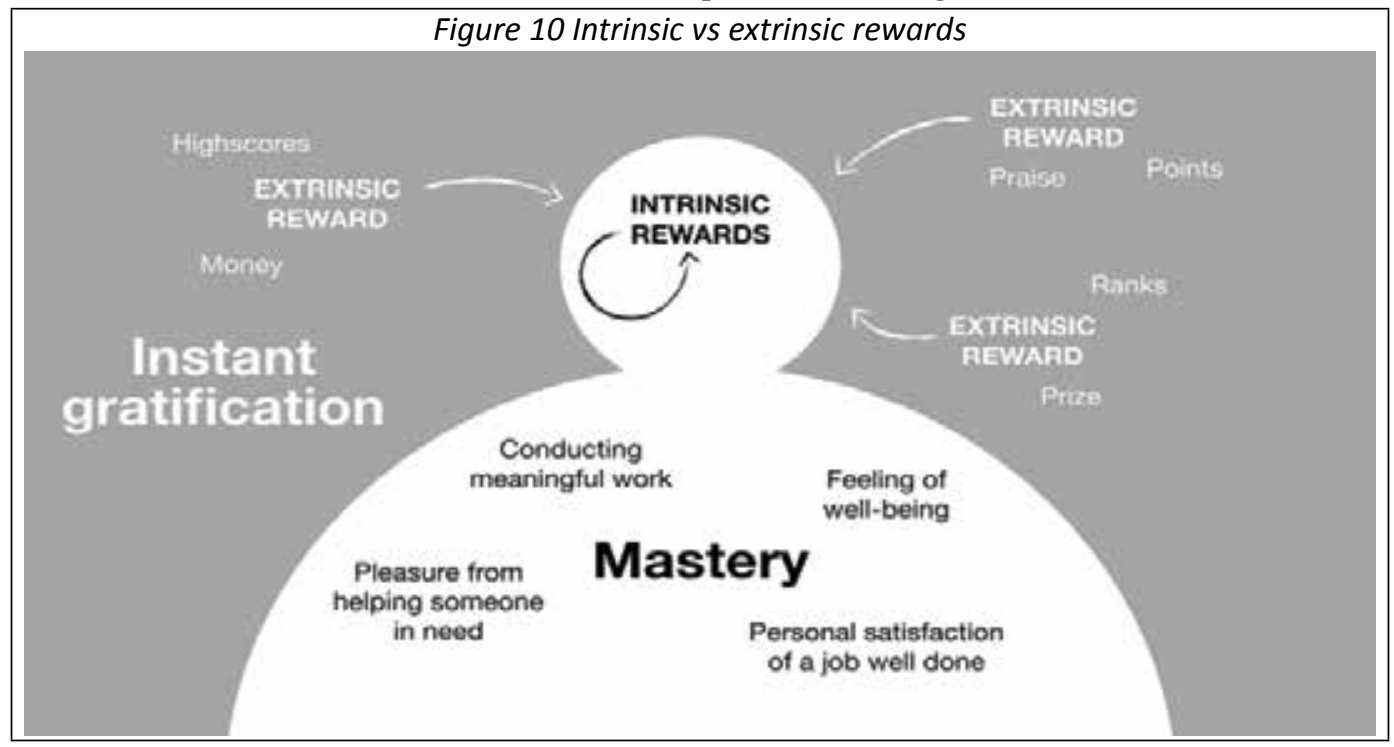

Intrinsic rewards: These are rewards that come from within the individual and reflect the satisfaction from doing the job and the opportunities for growth that the job provides. With proper management leadership intrinsic rewards may have motivational effects as strong or even stronger that extrinsic rewards. Many organizations ignore the influence of intrinsic rewards.

Extrinsic rewards: This is when one person reward another in recognition for a job well done. These rewards reinforce that the individual has distinguished themselves from the organization. Incentive compensation plans or pay for performance systems are reward systems that provide monetary (extrinsic) rewards based on measured results -achieving or exceeding some measured performance. This can only be successful if the organization's measurement system uses relevant and reliable performance information. The reward can be based on absolute performance, performance relative to some plan, or performance relative to some group.

\section{Summary and Conclusion}

Traditionally, most measures used in management accounting are financial in nature and emphasize on quantitative measures in managerial decision making process. Financial measures based systems are no longer appropriate in today's competitive business environment. Therefore, a larger entity of the management accounting system which assists in planning, monitoring and control of different organizational activities to optimize the use of resources, to support the process of decision making 
and to the performance evaluation process is known as management accounting and control system. It includes a comprehensive set of performance aspects consisting of both financial and non-financial measures. The scope of the MACS can be divided into two broad groups: technical considerations and behavioral considerations.

The technical aspect of well-designed MACS includes two categories: the relevance of the information and the scope of the system. Four characteristics accuracy, timeliness, consistency, and flexibility - measure the relevance of the information over the organization's entire value chain. The total life cycle costing accumulates product costs over the value chain. Other methods relating to total life cycle costing include target costing and kaizen costing. Target costing begins in the research, development and engineering stage of the value chain and provides the ability to control and reduce costs at all other stages of the value chain. Kaizen costing is an approach that can be used in the manufacturing process and enables to make small improvements in products during the production stage. Benchmarking assist managers in understanding the best practices of others ultimately how to apply and what they learn to their own organizations. The balanced scorecard integrates financial and non-financial measures derived from strategy into clear objectives, measures and initiatives. The scorecard is built around four perspectives: the financial, the customer, internal business process, and innovation and learning. For each of the perspective, specific performance measures are developed in a balanced fashion.

The behavioral aspect of MACS include key four characteristics based on human psychology and motivation. Ethical code of conduct help organizations deal with ethical dilemmas between individuals and organizational values and support to align the goals of individuals with those of the organization. Development and use of the right kinds of performance measures are tied directly into the second behavioral characteristics, which involves using a mix of short and long-term qualitative and quantitative measures. The third characteristics acknowledge that people are the organization's greatest assets. Developing an appropriate incentive system to reward performance is the fourth characteristics of the MACS. Both intrinsic and extrinsic rewards should use by organizations to motivate employees.

\section{References}

Atkinson, A.A., Kaplan, R.S., Matsumura, E.M., Young, S.M., \& Kumar, G.A. (2014). Management accounting information for decision making and strategy execution, (6th ed.). New Delhi: Pearson Education, Inc.

Camp, R.C., (1989). Benchmarking: the search for best practices that lead to superior performance. Quality Progress, IV, 62-69.

Cooper, R., \& Chew, W. B. (1996). Control tomorrow's costs through today's designs. Harvard Business Review (January-February) 88-97.

Ghalayini, A. M., Noble, J. S. \& Crowe, T. J. (1997). An integrated dynamic performance measurement system for improving manufacturing competitiveness. International Journal of Production Economics, 48, 207-225.

Imai, M. (1986). Kaizen: The key to Japanese competitive success. New York: McGraw Hill. Institute of Management Accountants [IMA]. (2008). Definition of management accounting. 
Retrieved from http://www.imanet.org/PDFs/Public/Research/SMA/Definition\%20of\%20 Management \%20Accounting.pdf

Kaplan, R. S. \& Norton, D. P. (1992). The balanced scorecard - measures that drive performance. Harvard Business Review, 70 (5), 71-79.

Sakurai, M. (1989). Target costing and how to use it. Journal of Cost Management for the Manufacturing Industry. Summer 1989, 39-50

Watson, G.H., (1993). How process benchmarking supports corporate strategy. Planning Review, 21 (I), 12-15.

Zairi, M., (1992). The art of benchmarking using customer feedback to establish performance gap. Total Quality Management, 3 (2), 177-188. 